\title{
Impact of a family caregiver training program in Kolkata, India on post-operative health perceptions and outcomes of cardiothoracic surgical patients
}

\author{
Jessie Liu1, Shahed S Alam², Rahul Guhabiswas³, Malikah S Waajid ${ }^{4}$, Somatree Chakrabarty², \\ Rajanita Das Purkayastha', Rita Popat ${ }^{5}$, Rajesh Gupta ${ }^{6}$ \\ ${ }^{1}$ Contra Costa Regional Medical Center, Family Medicine, Martinez, California, USA, 2 Noora Health, San Francisco, California, USA, ${ }^{3}$ Department of \\ Anesthesia, Rabindranath Tagore International Institute of Cardiac Sciences - Narayana Health, Kolkata, India, ${ }^{4}$ Georgia State University, Department \\ of Epidemiology, School of Public Health, Atlanta, Georgia, USA, 5 Stanford University, Health Research \& Policy, Stanford, California, USA, 6 Stanford \\ University, Center for Innovation in Global Health, Stanford, California, USA \\ Keywords: global health \\ https://doi.org/10.29392/joghr.3.e2019058
}

\section{Journal of Global Health Reports}

Vol. 3, 2019

\begin{abstract}
Background
Patient and family caregiver education is essential for adequate home care after a cardiothoracic surgical intervention. In resource-poor settings where access to medical care is limited and health literacy is low, pre-discharge caregiver education is frequently overlooked. This study evaluates the effect of the Care Companion Program (CCP), an in-hospital patient family engagement and education program that targets family caregivers to support post-surgical patient recovery.
\end{abstract}

\section{Methods}

This study was based on a quasi-experimental design at a tertiary care facility in Kolkata, India, in which 188 patient-caregiver dyads providing support to patients undergoing surgical intervention for cardiovascular disease were selected to participate. One hundred dyads received standard of care (SoC), and 88 dyads received the CCP. Patient-caregiver dyads were evaluated on patient post-discharge complications and physical functional status; Caregiver Activation Measure and health knowledge. Assessments were conducted at baseline, discharge, and post-discharge at 30 days.

\section{Results}

Post-discharge 30-day complication rates were significantly lower for the CCP group compared to SoC ( $34.4 \%$ vs. $14.5 \%$, respectively, P0.003). The CCP group showed a significantly greater increase in their Caregiver Activation Measure scores between baseline and discharge ( $4.2 \pm 9.1$ vs. $1.3 \pm 7.4$, respectively, $P<0.001)$ that were sustained at 30 days post-discharge ( $7.2 \pm 17.4$ vs. $1.4 \pm 10.4$, respectively, $P<0.001)$. Knowledge scores for the CCP group showed significant improvement $(P<0.001)$ between baseline and discharge and were sustained at 30 days post-discharge (P0.003). Compared to the SoC group, patients in the CCP group reported a significantly greater increase in their physical functional status (World Health Organization Quality of Life short form assessment (WHOQOL-BREF) physical health domain) between baseline and 30 days post-discharge $(P=0.018)$.

\section{Conclusions}

The results of the study suggest significant associations between participation in the CCP and reduced 30-day complications, increased caregiver activation, and increases in health knowledge. Programs such as the CCP may play an important role in engaging family caregivers to improve health outcomes in settings with limited healthcare resources.

Family caregivers play an essential role in the successful recovery of hospitalized patients by serving as the primary care providers following hospital stays. Integrating patient families as part of the care team can result in cost savings, enhanced patient and family experience of care, improved acute disease management, enhanced continuity of care, and prevention of hospital readmissions. ${ }^{1-7}$ Increased family engagement in the development of educational materials, program design, and patient care increases patient satisfaction, decreases anxiety among patients, and in some 
cases, improves health outcomes..$^{3,8,9}$ While family engagement is standard practice in several aspects of pediatric healthcare delivery, ${ }^{10-13}$ its role in adult healthcare is limited. ${ }^{14-16}$

Despite the growing body of knowledge surrounding the importance of integrating family members into the healthcare delivery process, there is a paucity of structured family member engagement interventions in hospitals, particularly in developing countries. In countries like India, family members are critical components of the health care process, due to healthcare worker shortages coupled with a communal social structure. ${ }^{17,18}$

Patients with cardiovascular disease (CVD), a condition largely driven by lifestyle factors that families can support, stand to benefit from increased family engagement. In India, CVD accounts for an estimated 2.6 million deaths annually ${ }^{19}$ and is a leading cause of non-communicable disease mortality. South Asians are particularly at a high risk of developing coronary artery disease $\mathrm{e}^{20}$, and the burden of CVD in India is projected to continue increasing due to rapid urbanization, population growth, and an aging population. ${ }^{21}$ Among individuals who undergo major cardiovascular surgeries, there is evidence to suggest patient and family education comprised of proper post-discharge care may prevent post-discharge surgical complications and improve quality of life. ${ }^{9,22}$

However, there are a number of challenges to increased family engagement in India within the healthcare setting, including cultural and social diversity, high patient volume, low health literacy and socioeconomic status (SES), and language barriers. ${ }^{23}$ Implicit bias against patient families based on demographics (rural or poor backgrounds, religious groups, castes, etc.), often impedes collaboration between health care professionals and patient families. ${ }^{24}$ Furthermore, while there is an emerging network of robust quaternary and tertiary care centers, the existing disconnect between these centers and primary care centers results in the lack of follow-up healthcare. ${ }^{25,26}$ Thus, there is a need for building the capacity of patients and family caregivers to provide home care and learn precautions post-hospitalization. ${ }^{27,28}$

This study explores the potential of families to provide efficacious care for a family member in settings with limited healthcare resources. The primary aim of this study is to assess the impact of an inpatient family caregiver training program (i.e. the Caregiver Companion Program (CCP)) on patient-level health outcomes and caregiver competencies for patients with CVD. The guiding research questions were as follows: 1) does the CCP impact post-discharge patient outcomes after cardiothoracic surgery with regard to postdischarge complications and physical functional status? and 2) does the CCP impact family caregiver engagement with regard to knowledge, confidence, and self-efficacy? This study was based on a quasi-experimental design. Randomization was not possible due to information sharing between participants that were observed during pilots of the intervention.

\section{METHODS}

\section{SETTING AND STUDY PARTICIPANTS}

Narayana Health-Rabindranath Tagore International Institute of Cardiac Sciences (RTIICS) is a 550-bed tertiary care facility located in Kolkata, India, with a catchment area including West Bengal, Bihar, and Bangladesh.

Study inclusion for patients was limited to participants aged 18 years and older with CVD admitted to RTIICS for open cardiothoracic surgery during the study enrollment period, with at least one accompanying family member considered to be a caregiver. Caregiver participants were limited to those aged 18 years and older and self-identified as the primary caregivers for their respective patient participant. Participation was limited to patients and caregivers who spoke Bengali or Hindi, the major languages in the region, as their primary language.

Recruitment and consent were conducted by two trained research assistants. The research team was notified of eligible participants by hospital admissions staff. Participants provided written informed consent in their primary language for participation in all three surveys (at pre-operation, discharge, and 30-days post-discharge) and a medical chart review. Additionally, prior to inviting family members to participate, patients confirmed permission to conduct surveys with a specified family member about their health and treatment.

\section{ETHICS}

Ethical clearance was granted through Stanford University's Institutional Review Board and the Narayana Health-Rabindranath Tagore International Institute of Cardiac Sciences Independent Ethics Committee, Kolkata, India. Informed consent for all patients and caregivers who participated in the study was obtained in writing.

\section{STUDY INTERVENTIONS}

\section{STANDARD OF CARE}

RTIICS provided conventional patient education and information sharing practices for cardiothoracic surgical patients in India. Physicians provided health education specific to the surgery during consultations at pre-operation clinic visits, at discharge from the hospital, and at post-operational clinic visits. Inpatient dietitians and physiotherapists provided individual nutrition and activity plans. At the time of discharge, nurses conducted a counseling session covering home care prepared by physicians, including medications, precautions, and plan for follow-up care.

\section{CARE COMPANION PROGRAM (CCP) INTERVENTION}

The CCP is an in-hospital family caregiver engagement, education, and training program developed using human-centered design ${ }^{29}$ and implemented by Noora Health. The content for the health skills imparted during the training is based on National Institutes of Health and American Heart Association best practices for cardiac health behaviors recommended after cardiothoracic surgery. ${ }^{30}$ Caregiver partic- 
ipants received education and training in post-surgical care hygiene, physical therapy, monitoring fluid balance and bowel movements, taking and recording vital signs, assisting with incentive spirometry and breathing exercises, taking medications, nutrition, exercise/activity restrictions, and recognizing warning signs.

Program implementation began with standardizing the patient-family engagement process with the hospital administration and clinical staff to ensure adequate integration into the care delivery framework. In addition, two nurses were selected by the administration to be the primary educators in the program and were trained by Noora Health in adult learning theory and soft skills to engage learners in individual and group teaching sessions.

Daily group training sessions and individualized practical teachings were conducted by an educator in either of the local languages of Bengali or Hindi. Each group session lasted approximately 75 minutes, with 30 minutes of narrative-driven short videos, 30 minutes of demonstration and practice, and 15 minutes of evaluation and question \& answer. Session sizes ranged from 3-10 participants. Each participant attended one session. Participants then opted into individual practical coaching with the nurse educator at the patient's bedside lasting 15-45 minutes, after the patient was shifted out of the intensive care unit (ICU). Caregivers who completed the group CCP training had the option of extended visiting hours to practice the skills they had learned while the patient was still in the hospital.

\section{PATIENT AND CAREGIVER SURVEY DATA COLLECTION}

Two research assistants who spoke Bengali, Hindi, and English fluently were trained in survey administration. All surveys were piloted with the target patient and caregiver populations prior to the start of study data collection. During piloting there was consistent agreement between the research assistants in administering the survey instruments. Interviews were conducted by the research assistants with consenting patients and caregivers when they were in the hospital for baseline and discharge surveys, and over the phone for 30-day surveys. Survey administration required 15-20 minutes for baseline and discharge surveys, and 20-40 minutes for the 30-day surveys.

\section{RECRUITMENT AND STUDY DESIGN}

Patients receiving SoC were recruited along with their stated family caregiver for the SoC group from beginning of July to mid-October 2014. The CCP was implemented end of October to the beginning of November 2014. The CCP patient-caregiver recruitment followed subsequently from mid-November 2014 to end of January 2015. Intention to treat analysis included participating intervention dyads regardless of their completion of the CCP. Primary reasons for non-participation in the CCP were conflict with class timing and anxiety about being in the hospital.

\section{OUTCOME MEASURES}

\section{POST-DISCHARGE COMPLICATIONS}

Previous studies have shown agreement of patient-reported post-surgical complications with surgeon-evaluated clinical diagnoses or chart review. ${ }^{31,32}$ Given the lack of data available from hospital records, ${ }^{33}$ potential for selection bias with chart review, and the general lack of consistent documentation of clinical visits in hospital records, complications data was collected via 30-day calls through the following algorithm (more information in Appendix S1). Two senior physicians at RTIICS defined and identified the necessary and sufficient signs and symptoms to determine athome patient-reported complications that would be reliably identified and communicated by patients at home, out of a list of post-discharge surgical complications by the U.S. Patient Safety Indicators. The two complications that could be reliably identified were superficial incisional surgical site infections (SSI) of the chest incision or leg incision and signs of lower respiratory infection. The definition used for SSI, per U.S. Center for Disease Control guidelines, ${ }^{34,35}$ was presence of any purulent discharge, even without laboratory confirmation, with the local-context, additional definition of any incision that produces discharge more than 5 weeks after the procedure with redness and swelling, with no other recognized cause. Since lower respiratory infections in India are often treated in an outpatient setting without imaging or laboratory confirmation, the definition of lower respiratory infection required either clinical diagnosis by a doctor or concurrence of high fever, new-onset cough, difficulty breathing, and severe fatigue. This latter definition is aligned with the CDC clinical definition of pneumonia of a fever of at least $38^{\circ} \mathrm{C}$, new onset cough, and signs of worsening gas exchange. ${ }^{36}$ The composite outcome of any complication was operationally defined such that if patients had more than one complication, they were only counted once.

Healthcare utilization for emergent issues was also recorded based on caregivers and patient report of outpatient or inpatient non-routine visits and the reason for each visit during the 30-day survey. Of note, all procedures were open cardiac surgical procedures, and all vein harvests were open. No endoscopic procedures were performed.

\section{QUALITY OF LIFE - PHYSICAL HEALTH DOMAIN}

The World Health Organization Quality of Life short form assessment (WHOQOL-BREF) in Bengali and Hindi was used to assess four domains: physical health (7 items), psychological health (6 items), social relationships (3 items), and environmental health (8 items), along with 2 items that measured overall quality of life. ${ }^{37}$ Scores were adjusted per WHOQOL-BREF scoring protocol and could not be calculated for cases that did not answer 2 or more questions in each domain (or 1 or more question in the social relationships domain). The survey was administered pre-operatively and post-operatively at 30 days post-discharge (more information in Appendix S1 of the Online Supplementary Document). The psychological, social relationships, and environmental domains were captured at 30 days post-dis- 
charge (Appendix S2 of the Online Supplementary Document).

\section{CAREGIVER ACTIVATION MEASURE}

The Caregiver Activation Measure (CG-PAM) was used to assess the primary caregiver's ability to effectively participate in care (Insignia Health, LLC 2011). The CG-PAM is a validated version of the Patient Activation Measure (PAM) intended to assess caregiver knowledge, skills, and confidence for health management (more information in Appendix S1 of the Online Supplementary Document). The CGPAM measures respondents on a 0-100 scale, with a higher score indicating greater activation. This instrument was administered prior to operation, at discharge, and 30 days after discharge. ${ }^{38}$ In addition, the patient activation measure was also administered at discharge to patients. While the intervention did not target patients, this was measured to inform any baseline variation in individual patient activation that may also influence health outcomes.

\section{KNOWLEDGE ON CARDIAC HEALTH MANAGEMENT}

Caregiver knowledge regarding topics related to cardiac health and the patient's care were assessed through two 10-item instruments developed for this study, each scored from 0-10. Two distinct instruments to assess knowledge were used due to concern for learning to questions from prior testing. One version was administered prior to operation and at discharge, and another version at 30 days after discharge (more information in Appendix S1 of the Online Supplementary Document).

\section{HOSPITAL SATISFACTION}

Both patients and caregivers were asked to rate the hospital based on their stay on a $0-10$ scale, with 10 being the "best hospital possible”. For analysis, scores were categorized into a binary measure of highly satisfied (scores of 9 or 10) or not highly satisfied (all other scores).

\section{DATA FROM MEDICAL RECORDS}

Discharge summary reports, written by the patient's surgeon and their medical secretaries, were obtained through HINAI, the electronic medical records system at RTIICS. Information gathered from these discharge summary reports included the surgical procedure, site and number of grafts or valve repairs/replacements, comorbidities (diabetes, hypertension, COPD, asthma, smoking), any complications recorded during the hospital course, and post-operative hospital length of stay.

\section{DATA ANALYSIS}

Data were collected using paper surveys administered inperson at baseline and by telephone post-discharge. Survey results were subsequently double-entered into a Microsoft Excel database by a data entry contracting service, Hi-Tech Outsourcing Services. STATA version 13.1 (STATA Corp, College Station, TX, USA) was used for all analyses. Patientcaregiver dyads were only included in analysis if either pa- tient or caregiver completed a 30-day survey, because the primary outcome measures of interest were assessed at the 30-day survey or were measured at baseline and 30 days after discharge. No missing data were imputed. Statistical significance was set at $P<0.05$ and all statistical tests were twotailed. Baseline differences between the two groups (SoC and intervention) were assessed with t-tests and chisquare. Continuous variables were plotted and assessed for normality. For continuous outcomes (such as activation scores, QOL, and knowledge), multivariable linear regression models were used and the slope (regression coefficient) and $95 \%$ confidence interval CI were estimated to evaluate the effect of the intervention compared to SoC. Adjustment factors were decided a priori. Outcome measures from caregiver responses were adjusted for caregiver age, sex, religion, education level, previous caregiving experience, rural vs. urban habitation, and patient procedure and diabetes status. Patient outcomes were also adjusted for patient age, sex, religion, education level, rural vs. urban habitation, smoking and diabetes status, and caregiver's previous caregiving experience. Residuals for all outcome variables were examined to check that model assumptions were satisfied. The demographic and medical independent variables were assessed for collinearity. For binary outcomes such as those related to complications, multivariable logistic regression models were used and odds ratios OR and 95\% CI were estimated to evaluate the effect of the intervention.

\section{RESULTS}

Within the standard of care control (SoC) group, 157 patients were invited to participate, of which 105 patientcaregiver dyads were enrolled. In the CCP intervention group, 137 patients were invited, and 110 dyads enrolled (Figure 1). Patients and caregivers declined primarily due to anxiety about signing the consent form or scheduling conflicts for the interview timing. Loss to follow-up at 30 days after discharge within the SoC arm was $9 \%$ for patients and $13 \%$ for caregivers, and $23 \%$ of patients and $24 \%$ of caregivers in the CCP intervention group. Given that patientcaregiver dyads were included if either patient or caregiver completed a 30-day survey, the resulting attrition rate was $5 \%$ in the SoC arm and $20 \%$ in the intervention group. Per analysis of baseline characteristics, the subjects who were lost to follow-up were similar to those who remained.

\section{PARTICIPANT CHARACTERISTICS}

The SoC and intervention groups had similar distributions of patient and caregiver demographics (Table 1 and Table 2) and health metrics (Table 3). The mean age of the patients in the SoC group was 56.9 and in the intervention group was 54.5. Mean age of caregivers in the SoC group was 36.6 and for the intervention group was 39.4. Mean household size was 5 members for families in the SoC group and the intervention group. The sum of material wealth items-mobile phone, clock/watch, electricity, fan, AC, TV, computer, refrigerator, car, motorcycle, tractor-was similar measuring $6.65 \pm 2.33$ and $6.72 \pm 1.70$ for patients in the SoC and intervention groups, respectively. 
Table 1. Patient demographics

\begin{tabular}{|c|c|c|c|}
\hline Variable & SoC (100), $n^{*}(\%)$ & Intervention (88) n ${ }^{*}$ (\%) & $P$-value \\
\hline Gender & & & 0.522 \\
\hline Male & $80(80)$ & $67(78)$ & \\
\hline Female & $20(20)$ & $21(22)$ & \\
\hline Education & & & 0.319 \\
\hline None & $12(12)$ & $7(8)$ & \\
\hline Less than high school & $37(38)$ & $41(5)$ & \\
\hline High school or higher & $49(50)$ & $37(44)$ & \\
\hline [missing] & 2 & 3 & \\
\hline Literacy & & & 0.079 \\
\hline Can read \& write & $84(87)$ & $62(78)$ & \\
\hline Cannot read \& write & $12(13)$ & $18(22)$ & \\
\hline [missing] & 4 & 8 & \\
\hline Occupation: & 0.935 & & \\
\hline Works outside of home & $57(58)$ & $49(57)$ & \\
\hline Works in home & $42(42)$ & $37(43)$ & \\
\hline [missing] & 1 & 2 & \\
\hline Religion & & & 0.515 \\
\hline Hindu & $78(78)$ & $72(82)$ & \\
\hline Muslim & $22(22)$ & $16(18)$ & \\
\hline Living environment & & & 0.222 \\
\hline Urban & $62(62)$ & $62(70)$ & \\
\hline Rural & $38(38)$ & $26(30)$ & \\
\hline \multicolumn{4}{|l|}{ Comorbidities } \\
\hline Diabetes & $36(36)$ & $33(38)$ & 0.831 \\
\hline Hypertension & $40(40)$ & $39(44)$ & 0.549 \\
\hline Asthma/COPD & $11(11)$ & $11(13)$ & 0.750 \\
\hline Smoking & $23(23)$ & $24(27)$ & 0.500 \\
\hline
\end{tabular}

SoC - standard of care, $\mathrm{N}$ - number of patients

*Number may not add up due to missing information by respondents.

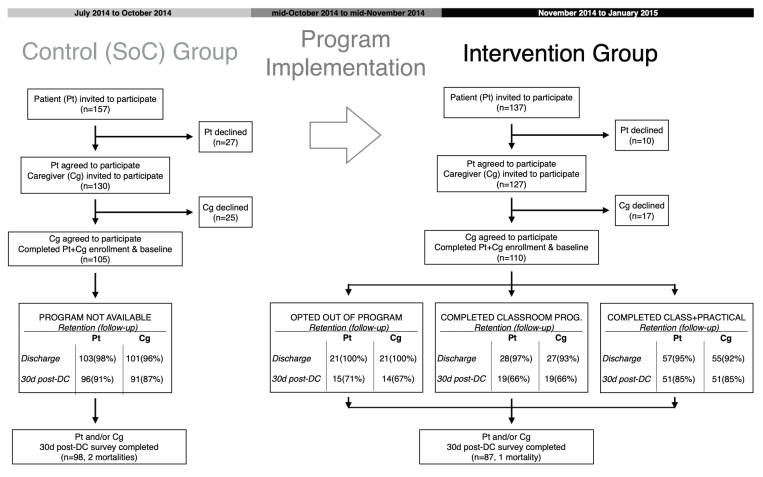

Figure 1

Study recruitment and participation.

Notable differences in the two groups includes the family members who reported caregiving experience, where the SoC group's caregivers reported significantly more experience $(P=0.028 ; 30 \%$ in the intervention group compared to $50.0 \%$ in the SoC group,Table 2 ). At baseline, the caregivers in the SoC group reported worse self-rated health $(P<0.001$; $20.0 \%$ in the intervention group compared to $37.1 \%$ in the SoC group). Patient Activation Measure of the SoC group was higher than in the intervention group $(P=0.054,57.5$, $\mathrm{SD} \pm 17.5$ and $52.5 \mathrm{SD} \pm 14.9$ respectively,Table 3$)$. The patients were not targeted by the intervention.

\section{POST-DISCHARGE SURGICAL COMPLICATIONS}

The composite outcome of incidence of all-cause post-discharge complications was significantly lower in the intervention arm compared to SoC (Table 4). However, when stratified by type of complications, this did not reach statistical significance due to smaller numbers, although the trend was similar to the composite outcome. These complications included lower respiratory infection, chest incision wound infection, and-for those patients who had a saphenous vein harvested-leg incision wound infection. The incidence of any at home adverse event 30-days post-discharge was significantly lower for the intervention group, with adjusted results demonstrating a reduction of $71 \%$ (adjusted OR 0.29, 95\% CI=0.13-0.66, $P=0.003$ ). 
Table 2. Caregiver demographics

\begin{tabular}{|c|c|c|c|}
\hline$\overline{\text { Variable }}$ & SoC (100), $n^{*}(\%)$ & Intervention (88), $\mathrm{n}^{*}(\%)$ & $P$-value \\
\hline Gender: & & & 0.305 \\
\hline Male & $61(61)$ & $60(68)$ & \\
\hline Female & $39(39)$ & $28(32)$ & \\
\hline Education: & & & 0.319 \\
\hline None & $1(1)$ & $4(5)$ & \\
\hline Less than high school & $32(33)$ & $27(31)$ & \\
\hline High school or higher & $65(66)$ & $55(64)$ & \\
\hline Literacy: & & & 0.589 \\
\hline Can read \& write & $89(93)$ & $76(90)$ & \\
\hline Cannot read \& write & $7(7)$ & $8(10)$ & \\
\hline [missing] & 4 & 4 & \\
\hline Religion: & & & 0.290 \\
\hline Hindu & $78(78)$ & $74(84)$ & \\
\hline Muslim & $22(22)$ & $14(16)$ & \\
\hline Language: & & & 0.492 \\
\hline Bengali & $79(79)$ & $73(83)$ & \\
\hline Hindi & $21(21)$ & $15(17)$ & \\
\hline Occupation: & & & 0.329 \\
\hline Works outside of home & $63(66)$ & $51(59)$ & \\
\hline Works in home & $33(34)$ & $36(41)$ & \\
\hline [missing] & 2 & 1 & \\
\hline Health self-rating: & & & 0.001 \\
\hline Very good-Excellent & $24(24)$ & $12(14)$ & \\
\hline Good & $38(38)$ & $57(65)$ & \\
\hline Fair-Poor & $38(38)$ & $19(22)$ & \\
\hline Marital status: & & & 0.499 \\
\hline Single & $22(23)$ & $23(27)$ & \\
\hline Married & $76(78)$ & $63(73)$ & \\
\hline [missing] & 2 & 2 & \\
\hline Relationship to patient & & & 0.445 \\
\hline Spouse & $28(28)$ & $29(33)$ & \\
\hline Son/Daughter & $47(47)$ & $38(43)$ & \\
\hline Sibling & $5(5)$ & $8(9)$ & \\
\hline Other relative & $18(18)$ & $13(15)$ & \\
\hline Friend & $2(2)$ & 0 & \\
\hline Living situation: & & & 0.874 \\
\hline Lives with patient & $76(76)$ & $66(75)$ & \\
\hline Does not live with patient & $24(24)$ & $22(25)$ & \\
\hline Shared caregiving: & & & 0.795 \\
\hline Sole caregiver & $13(14)$ & $11(13)$ & \\
\hline Multiple caregivers & $78(86)$ & $74(87)$ & \\
\hline [missing] & 9 & 3 & \\
\hline Caregiving experience: & & & 0.028 \\
\hline Had previous experience & $50(50)$ & $30(34)$ & \\
\hline No previous experience & $50(50)$ & $58(66)$ & \\
\hline
\end{tabular}

SoC - standard of care, $\mathrm{N}$ - number of patients

*Number may not add up due to missing information by respondents. 
Table 3. Patient clinical characteristics

\begin{tabular}{|c|c|c|c|}
\hline Variable & SoC (100), n* (\%) & Intervention (88), n* (\%) & $P$-value \\
\hline Procedure: ${ }^{\dagger}$ & & & 0.391 \\
\hline CABG & $81(81)$ & $61(71)$ & \\
\hline Single valve replacement & $11(11)$ & $12(14)$ & \\
\hline Double valve replacement & $3(3)$ & $5(6)$ & \\
\hline CABG \& single valve replacement & $2(2)$ & $4(5)$ & \\
\hline Other & $3(3)$ & $4(5)$ & \\
\hline In-hospital post-surgical complication: $† \ddagger$ & & & 0.419 \\
\hline Yes & $17(22)$ & $11(17)$ & \\
\hline \multirow[t]{2}{*}{ Missing } & 24 & 23 & \\
\hline & SoC (100), MeanSD & Intervention (88), MeanSD & \\
\hline \multicolumn{4}{|l|}{ Health metrics:‡ } \\
\hline Ejection fraction pre-op & 0.526 .110 & 0.537 .108 & 0.635 \\
\hline Ejection fraction post-op & 0.544 .092 & 0.553 .097 & 0.682 \\
\hline BMI & 22.9783 .50 & 23.0673 .20 & 0.859 \\
\hline Systolic BP & 125.12415 .82 & 125.22115 .18 & 0.968 \\
\hline Diastolic BP & 75.8648 .80 & 77.5589 .44 & 0.235 \\
\hline Patient activation measure & 57.48717 .53 & 52.48314 .93 & 0.054 \\
\hline
\end{tabular}

SoC - standard of care, $\mathrm{N}$ - number of patients, CABG - coronary artery bypass grafting, SD - standard deviation, op - operation, BMI - body mass index, BP - blood pressure, repl replacement

*Number may not add up due to missing information by respondents. Frequency \% exclude missing data.

†Data obtained from discharge summaries.

$\ddagger$ Evaluated at discharge instead of pre-operation.

Table 4. Surgical complications and mortality, 30-day discharge

\begin{tabular}{|c|c|c|c|c|c|}
\hline 30-day complications & $\begin{array}{c}\text { SoC } \\
(n=94)\end{array}$ & $\begin{array}{l}\text { Intervention } \\
\quad(n=81)\end{array}$ & $\begin{array}{l}\text { Crude OR } \\
(95 \% \mathrm{Cl})\end{array}$ & $\begin{array}{l}\text { Adjusted OR* } \\
(95 \% \mathrm{Cl})\end{array}$ & $\begin{array}{l}\text { P value, adjusted } \\
\text { model }^{*}\end{array}$ \\
\hline & No. (\%) & No. (\%) & & & \\
\hline All complications $†$ & $\begin{array}{c}33 \\
(34.4)\end{array}$ & $12(14.5)$ & $\begin{array}{l}0.32(0.15 \\
0.68)\end{array}$ & $0.29(0.13,0.66)$ & 0.003 \\
\hline $\begin{array}{l}\text { Lower respiratory } \\
\text { infection } \neq\end{array}$ & $8(8.3)$ & $0(0)$ & NE & NE & NE \\
\hline $\begin{array}{l}\text { Infection (chest } \\
\text { incision) }\end{array}$ & $5(5.2)$ & $2(2.4)$ & $\begin{array}{l}0.45(0.09 \\
2.38)\end{array}$ & $0.53(0.08,3.45)$ & 0.509 \\
\hline Infection (leg graft)§ & $\begin{array}{c}20 \\
(24.7)\end{array}$ & $10(15.4)$ & $\begin{array}{l}0.55(0.24 \\
1.29)\end{array}$ & $0.57(0.23,1.43)$ & 0.231 \\
\hline
\end{tabular}

SoC - standard of care, CI - confidence interval, OR - odds ratio, NE - not estimable

*Adjusted for patient age, sex, religion, educational level, rural vs. urban habitation, smoking and diabetes status, and caregiver's previous caregiving experience.

$\dagger$ Two patients had multiple complications in the SoC group. Each was only counted once.

$\ddagger$ Patients who had symptoms of possible LRI all had caregivers who had prior caregiving experience, so not estimable (NE),

§Only patients who had saphenous vein harvested included in analysis, ( $\mathrm{N}=81,65 \mathrm{for} \mathrm{SoC}$ and Intervention groups, respectively). All saphenous veins harvested open approach, not endoscopic.

\section{QUALITY OF LIFE - PHYSICAL HEALTH DOMAIN}

Patients in the intervention group showed significantly greater improvements in their physical functional status, per WHOQOL-BREF physical health domain scores, as compared to baseline (treatment effect, $1.0 ; 95 \% \mathrm{CI}=0.14-1.48$ ) (Figure 2).

\section{CAREGIVER ACTIVATION MEASURE}

Compared with each respondent's CG-PAM score at baseline, differences in Caregiver Activation Measure (CG-PAM) scores showed significantly greater increase in intervention group caregivers than SoC group when measured at discharge (treatment effect, $4.2 ; 95 \% \mathrm{CI}=2.4-8.2$ ) and at 30 days post-discharge (treatment effect, 7.2; $95 \%$ CI=6.43-15.89) (Figure 3).

\section{KNOWLEDGE ON CARDIAC HEALTH MANAGEMENT}

Differences in heart health knowledge scores for caregivers, compared to each of their own baseline knowledge scores, showed significant point-score improvement at discharge for intervention group compared to SoC group (+2.7, SD 2.4 


\section{DISCUSSION}

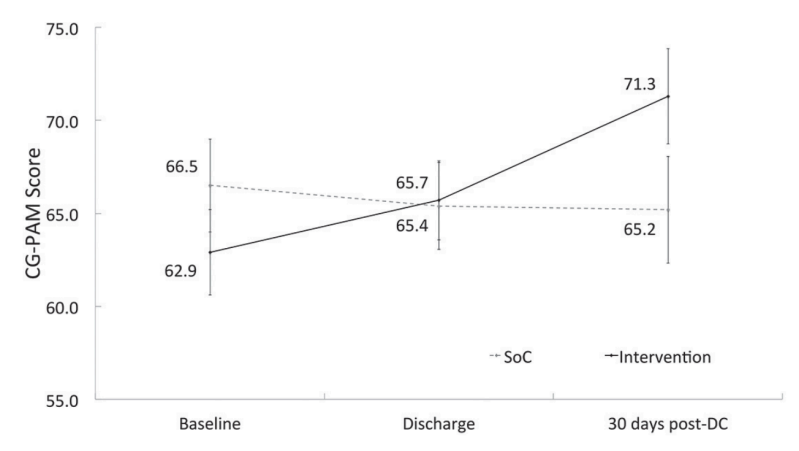

\section{Figure 2}

Adjusted means of patient physical health at baseline and 30 days post-discharge. WHOQOL-BREF, adjusted scores. $P=0.018$, calculated for difference between 30 days post-discharge and baseline. Error bars indicate standard deviation. Adjusted for patient age, sex, religion, educational level, rural vs. urban habitation, smoking and diabetes status, and caregiver's previous caregiving experience.

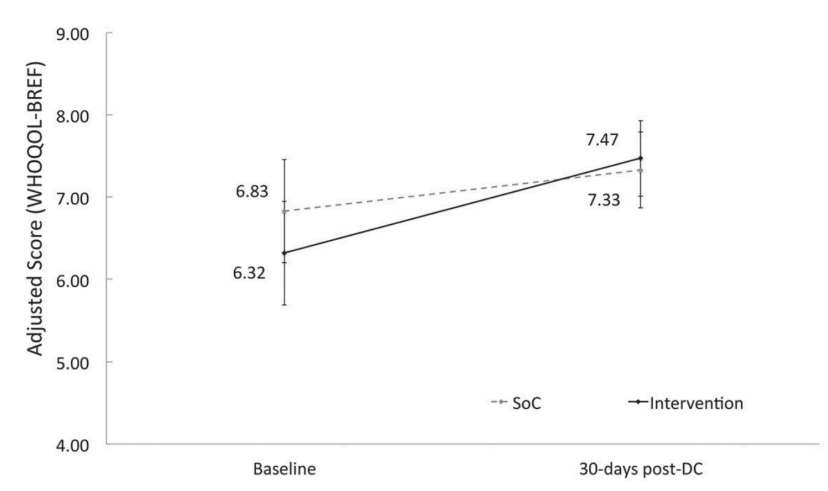

\section{Figure 3}

Adjusted means of Caregiver Activation Measure (CG-PAM) Scores at hospital admission, discharge, and 30 days post-discharge. $P<0.001$, calculated for difference between baseline and discharge; $P<0.001$, between baseline and 30 days post-discharge. Error bars indicate standard deviation. Adjusted for caregiver age, sex, religion, education level, previous caregiving experience, rural vs. urban habitation, and patient procedure and diabetes status.

vs. +0.7 , SD 1.3 , respectively, $P<0.001)$. At 30 days post-discharge, when a different set of questions were asked, individual caregivers in the intervention group outperformed the SoC group in comparison to each of their baseline knowledge scores $(P=0.003,1.26, \mathrm{SD} \pm 0.54$ vs. .22 , SD \pm 0.50 , Table 5).

\section{HOSPITAL SATISFACTION}

Participants in the intervention group reported being more highly satisfied with their overall hospital stay compared to those in the SoC group, with a crude OR=1.86 (95\% $\mathrm{CI}=1.02-3.40])$. When adjusted for patient age, sex, religion, and education level, patients whose caregivers participated in the intervention were still more satisfied with their hospital stay, with an adjusted $\mathrm{OR}=1.70$ (95\% CI=0.90-3.18). A parallel satisfaction was demonstrated among caregiver participants, with crude $\mathrm{OR}=1.60$ (95\% $\mathrm{CI}=0.87-2.96$ ), and adjusted for caregiver age, sex, religion, education level, and caregiving experience, $\mathrm{OR}=1.71$ (95\% CI=0.89-3.29).
The Care Companion Program (CCP) family caregiver training program is a novel family engagement model implemented within a healthcare treatment facility in India. The aim of the study was to examine the impact of CCP participation on family caregiver health-related competencies and patient-level health outcomes following adult cardiothoracic surgery. Overall, this study supports findings in previous studies that small changes in hospital policy and practice that promote family-centered care may result in an array of positive outcomes.

Caregivers in the intervention group exhibited greater increases in cardiac health-related knowledge at discharge and at 30 days post-discharge, suggesting effective transfer of health information through CCP's didactic components. This alone is likely insufficient to prompt changes in health-promoting behaviors. ${ }^{39}$ A greater predictor of clinically-significant performance of healthy behaviors is activation.

Improvement in the Caregiver Activation Measure from baseline was found in the intervention group at discharge and at 30 days post-discharge. The CAM was used as a standardized approach to explore the differences in general health knowledge, skills, and confidence of the family caregivers. Increased patient activation is well-accepted as contributing to improved performance of health-promoting behaviors and engagement. Within the context of the study population, in which family members are often more engaged than patients in healthcare decision-making and home care, increased caregiver activation would be expected to have tangible benefits for patient outcomes.

The increase in family caregiver activation seen in the intervention group may contribute to greater physical and mental functional status of the patient, which would be compatible with previous work that has found similar associations. ${ }^{40}$ Patients in the intervention group showed greater improvements in their WHOQOL-BREF physical health domain, as compared to each patient's baseline score. This may be attributed to caregivers' increased awareness and assistance in helping patients with activities of daily living and emotional care.

Additional findings indicate that family caregiver training shows promise for decreasing post-discharge complications for cardiothoracic surgery patients. Averting preventable complications improves recovery and reduces avoidable healthcare utilization, especially important for lower-resource populations. In the intervention group, there was a statistically significant lower rate of patientreported post-surgical complications. However, the effect became non-statistically significant when separated out by specific complications of wound infection and pneumonia. Decreased rates in complications may be attributed to improved caregiver knowledge and activation.

The intervention may also have a considerable effect on a patient's overall hospital experience. This change was reflected in results showing an increase in satisfaction by patients and caregivers with the care provided. Improved satisfaction scores and increased confidence mirror findings from previous studies on interventions that increase family engagement in a clinical setting. 6,41 
Table 5. Adjusted means of caregiver knowledge, at baseline, discharge, and 30-days post-discharge

\begin{tabular}{|c|c|c|c|c|}
\hline Knowledge score (out of 10) & SoC & Intervention & $\begin{array}{l}\text { Treatment } \\
\text { effect }\end{array}$ & $\begin{array}{l}\text { Pvalue, } \\
\text { adjustedmodel* }\end{array}$ \\
\hline & $\begin{array}{l}\text { Mean* } \pm S D \\
\text { (n) }\end{array}$ & $\begin{array}{l}\text { Mean* } \pm S D \\
(n)\end{array}$ & $(95 \% \mathrm{Cl})$ & \\
\hline Baseline & $\begin{array}{l}6.15 \pm .72 \\
(100)\end{array}$ & $\begin{array}{l}5.02 \pm .70 \\
(87)\end{array}$ & $\begin{array}{l}1.13(1.62 \\
0.57)\end{array}$ & $<0.001$ \\
\hline Discharge & $\begin{array}{l}6.96 \pm .75 \\
(96)\end{array}$ & $\begin{array}{l}7.84 \pm .73 \\
(84)\end{array}$ & $\begin{array}{l}0.88(0.30 \\
1.56)\end{array}$ & 0.004 \\
\hline 30-day post-discharge $\dagger$ & $\begin{array}{l}4.89 \pm .91 \\
(89)\end{array}$ & $\begin{array}{l}4.84 \pm .81 \\
\quad(83)\end{array}$ & $\begin{array}{l}0.050 .69 \\
0.76)\end{array}$ & 0.919 \\
\hline Mean difference (discharge vs. baseline) & $\begin{array}{l}0.72 \pm .45 \\
\quad(96)\end{array}$ & $\begin{array}{l}2.79 \pm .52 \\
\quad(84)\end{array}$ & $\begin{array}{l}2.77(1.48 \\
2.65)\end{array}$ & $<0.001$ \\
\hline $\begin{array}{l}\text { Mean difference (30-day post-discharge vs. } \\
\text { baseline†) }\end{array}$ & $\begin{array}{c}1.26 \pm .54 \\
(89)\end{array}$ & $\begin{array}{l}0.22 \pm .50 \\
(82)\end{array}$ & $1.04(.37,1.83)$ & 0.003 \\
\hline
\end{tabular}

SoC - standard of care, $\mathrm{n}$ - number of patients, SD - standard deviation

*Adjusted for caregiver age, sex, religion, education level, previous caregiving experience, rural vs. urban habitation, and patient procedure and diabetes status.

$\dagger 10$-question set was the same between baseline and discharge, but was different, though on similar material, for 30-day post-discharge.

There are several limitations to this study. One of the primary challenges during the study protocol implementation was attrition as a result of incomplete 30-day followup and an unexpected human resource constraint on the research team that prevented conduction of 30-day surveys during a two-week period for the intervention group. As is generally standard in survey-administered studies, $12.6 \%$ of patient-caregiver dyads were lost due to dropout by the 30-day post-discharge survey. However, analyses of data from the pre-operative and discharge survey results showed no significant demographic differences between those for whom 30-day calls were completed versus not completed. Another limitation to the study was the use of non-equivalent groups as a SoC; because randomization wasn't used, there was no way to ascertain whether the groups differed on variables that were not measured in the study. Potential bias may have been introduced into the study with differing baseline characteristics in caregivers between the $\mathrm{SoC}$ and intervention groups; differences between groups for patient literacy and Patient Activation Measure would be expected to bias toward the null, and although health self-rating of caregivers favors the intervention group, prior caregiving experience favors SoC. Due to contextual limitations of inconsistent post-operative clinic visits and laboratory data, study data relied on patient or caregiver-reported information for evaluating complications, which is limited by recall bias with respect to the reliability of self-reported complication measures. Additional limitations to the study were the small sample size, short time frame between data collection points and single-site design.

The results should be further validated with future studies using a randomized experimental design and a larger sample size with data collection at time points further out from intervention initiation. Measuring indicators beyond 30 days would yield valuable information about the longerterm effects of such programs. Additional research on the post-discharge complication rates of patients in India would be required to provide better context surrounding the recovery of patients after major surgeries. Incorporating standardized provider-based complication data would be ideal. A robust mixed-methods study that incorporated home visits would also be beneficial, to qualitatively evaluate impact of this program on the family unit and to confirm any reported behavior changes. Given the communal Indian social context, and secondary findings of participants sharing information with others, additional research on potential snowball effect of caregiver training and the accuracy of information transfer would also add to existing knowledge. The impact of an intervention such as this one may also be explored in other geographic contexts.

\section{CONCLUSIONS}

Although the intervention studied here included only adult cardiothoracic surgery patients with CVD, the program structure lends itself to implementation for a variety of health conditions. By setting up a training infrastructure for patient families to formally learn skills that are integrated with hospital processes, their role within a hospital environment becomes more formalized and is perceived as more essential. A family caregiver training program would be particularly beneficial in clinical environments where there is a shortage of healthcare workers, disempowered patient populations, and an abundance of social capital provided by supportive patient family structures, one example being maternal child health (42).

Family training interventions are particularly effective during times of "health shocks" when internal and external motivations for health behavior change are greatest. The integration of family caregivers in healthcare delivery process is an innovative approach that serves to challenge the current paradigm and standard practice in the hospital discharge process and aftercare.

\section{ACKNOWLEDGEMENTS}

The authors are grateful to the Narayana Health Rabindranath Tagore International Institute of Cardiac Sciences for research coordination and support for survey ad- 
ministration, and to Noora Health for their collaboration and Care Companion Program development and implementation. The authors thank Dr. Grant Miller (Director of Stanford Center for International Development \& Associate Professor at the School of Medicine, Stanford University) for his guidance in study design and the Stanford University Department of Statistics, and Stanford Department of Medicine Quantitative Sciences Unit for assistance in data analysis. Lastly, the authors thank the support of Stanford School of Medicine Medical Scholars Program and Noora Health.

\section{ETHICS APPROVAL AND CONSENT TO PARTICIPATE}

This research study was approved by the Stanford University Institutional Review Board (IRB Protocol \#30499) and by the Rabindranath Tagore International Institute of Cardiac Sciences (RTIICS) Institutional Ethics Committee. Informed consent for all patients and caregivers who participated in the study was obtained in writing.

\section{AVAILABILITY OF DATA AND MATERIAL}

The datasets generate during and/or analyzed during the current study are fully available without restriction in the Harvard Dataverse database, Dataset ID: doi: 10.7910/DVN/ FSEAOF; available at: http://dx.doi.org/10.7910/DVN/ FSEAOF.

FUNDING

Stanford School of Medicine Medical Scholars Program was the primary funder for this study by supporting JL and SSA.
Noora Health (noorahealth.org) provided partial funding by supporting SC, RDP, and MSW. The funders had no role in study design, data collection and analysis, decision to publish, or preparation of the manuscript.

\section{COMPETING INTERESTS}

Jessie Liu is a co-founder and previously Impact Lead at Noora Health. During the period of the study, Jessie was supported through the Stanford University School of Medicine Medical Scholars Program. Shahed Alam is a cofounder and President at Noora Health. During the period of the study, Shahed was supported through the Stanford University School of Medicine Medical Scholars Program. Somatree Chakrabarty and Rajanita D. Purkayastha were supported through Noora Health's Division of Research (each an amount less than \$2500). Malikah Waajid received an unpaid fellowship through IDEX, a fellowship organization that Noora Health accepts fellows from. The authors have completed the Unified Competing Interest form at http://www.icmje.org/coi disclosure.pdf (available on request from the corresponding author) and declare no further conflicts of interest.

\section{CORRESPONDENCE TO:}

Shahed Alam

13803 Rosebranch Ct.

Houston, TX 77059

USA

shahed@noorahealth.org 


\section{REFERENCES}

1. Johnson B, Abraham M, Conway J, Simmons L, Edgman-Levitan S, Sodomka P, et al. Partnering with Patients and Families to Design a Patient-and FamilyCentered Health Care System. Institute for Patient-and Family-Centered Care and Institute for Healthcare Improvement; 2008.

2. Boudreaux ED, Francis JL, Loyacano T. Family presence during invasive procedures and resuscitations in the emergency department: a critical review and suggestions for future research. Ann Emerg Med. 2002;40(2):193-205. doi:10.1067/me m.2002.124899

3. Brumbaugh B, Sodomka P. Patient-and familycentered care-The impact on patient safety and satisfaction: A comparison study of intensive care units at an academic medical center. In: Proceedings of the 4th International Conference on Patient-and Family-Centered Care: Partnerships for Quality and Safety. ; 2009.

4. Chow SM. Challenging restricted visiting policies in critical care. Off J Can Assoc Crit Care Nurs. 1999;10:24-27.

5. Davidson JE, Powers K, Hedayat KM, et al. Clinical practice guidelines for support of the family in the patient-centered intensive care unit: American College of Critical Care Medicine Task Force 2004-2005. Crit Care Me. 2007;35(2):605-622. doi:10.1 097/01.ccm.0000254067.14607.eb

6. Fumagalli S, Boncinelli L, Lo Nostro A, et al. Reduced cardiocirculatory complications with unrestrictive visiting policy in an intensive care unit: results from a pilot, randomized trial. Circulation. 2006;113(7):946-952. doi:10.1161/circulationaha.10 $\underline{5.572537}$

7. Garrouste-Orgeas M, Philippart F, Timsit JF, et al. Perceptions of a 24-hour visiting policy in the intensive care unit. Crit Care Med. 2008;36(1):30-35. d oi:10.1097/01.ccm.0000295310.29099.f8

8. Harris MD. Shared medical appointments after cardiac surgery-the process of implementing a novel pilot paradigm to enhance comprehensive postdischarge care. J Cardiovasc Nurs. 2010;25(2):124-129. doi:10.1097/jcn.0b013e3181beb1 $\underline{24}$

9. Cebeci F, Çelik SŞ. Discharge training and counselling increase self-care ability and reduce postdischarge problems in CABG patients. J Clin Nurs. 2007;17(3):412-420. doi:10.1111/j.1365-2702.2007.01 952.x
10. American Academy of Pediatrics. Policy statement: Family-centered care and the pediatrician's role. Pediatrics. 2003;112(691). doi:10.1 542/peds.112.3.69112949306

11. Gooding JS, Cooper LG, Blaine AI, Franck LS, Howse JL, Berns SD. Family support and familycentered care in the neonatal intensive care unit: origins, advances, impact. Semin Perinatol. 2011;35(1):20-28. doi:10.1053/j.semperi.2010.10.004

12. Kuo DZ, Houtrow AJ, Arango P, Kuhlthau KA, Simmons JM, Neff JM. Family-centered care: current applications and future directions in pediatric health care. Matern Child Health J. 2012;16(2):297-305. doi:1 $\underline{0.1007 / \mathrm{s} 10995-011-0751-7}$

13. Committee on Hospital Care and Institute for Patient- and Family-Centered Care. Patient-and family-centered care and the pediatrician's role. Pediatrics. 2012;129(394):1015422011-308422291118. doi:10.1542/peds.2011-308422291118

14. Davidson JE. Family-centered care: meeting the needs of patients' families and helping families adapt to critical illness. Crit Care Nurse. 2009;29(3):28-34. $\underline{\mathrm{d}}$ oi:10.4037/ccn2009611

15. Morhardt D, Weintraub S, Khayum B, et al. The CARE pathway model for dementia: psychosocial and rehabilitative strategies for care in young-onset dementias. Psychiatr Clin North Am. 2015;38(2):333-352. doi:10.1016/i.psc.2015.01.005

16. Legg LA, Quinn TJ, Mahmood F, et al. Nonpharmacological interventions for caregivers of stroke survivors. Cochrane Database Syst Rev. 2011;(10):CD008179. doi:10.1002/14651858.cd00817 9.pub2

17. Chadda R, Deb K. Indian family systems, collectivistic society and psychotherapy. Indian J Psychiatry. 2013;55(6):299. doi:10.4103/0019-5545.10 $\underline{5555}$

18. World Health Organization. Towards an international consensus on policy for long-term care of the ageing. https://www.who.int/ageing/publicatio ns/long_term care/en/

19. World Health Organization. Noncommunicable diseases (NCD) country profiles: India. Published 2014. http://www.who.int/nmh/countries/ind_en.pdf

20. Chaturvedi N. Ethnic differences in cardiovascular disease. Heart. 2003;89(6):681-686. doi:10.1136/hear t.89.6.681 
21. Chauhan S, Aeri BT. The rising incidence of cardiovascular diseases in India: Assessing its economic impact. J Preventive Cardiol. $2015 ; 4: 735-740$.

22. Brown JP, Clark AM, Dalal H, Welch K, Taylor RS. Patient education in the management of coronary heart disease. Cochrane Database Syst Rev. 2011;(12):CD008895. doi:10.1002/14651858.cd00889 5.pub2

23. Ghosh S, Saha S, Koley M, Kundu M, Mondal R, Patra S. Access to and utilization of the health services among the patients in a government homeopathic hospital in West Bengal, India: a crosssectional study. J Evid Based Complementary Altern Med. 2014;19(4):247-252. doi:10.1177/215658721453 $\underline{8452}$

24. Srivatsan R. Reflections on discrimination and health in India. Indian J Med Ethics. Published online January 1, 2015. doi:10.20529/ijme.2015.004

25. Boltz M, Resnick B, Chippendale T, Galvin J. Testing a family-centered intervention to promote functional and cognitive recovery in hospitalized older adults. J Am Geriatr Soc. 2014;(62):2398-2407. $\underline{\mathrm{d}}$ oi:10.1111/igs.13139

26. Planning Commission of India. High level expert group report on universal health coverage for India. Published 2011. http://planningcommission.nic.in/re ports/genrep/rep uhc0812.pdf

27. Reddy KS. India's aspirations for universal health coverage. N Engl J Med. 2015;373(1):1-5. doi:10.1056/ nejmp1414214

28. Jagannathan A. Family caregiving in India: Importance of need-based support and intervention in acute care settings. J Postgrad Med. 2014;60(4):355. doi:10.4103/0022-3859.143950

29. Hasso Plattner Institute of Design at Stanford. d.School: Our point of view. Published 2015. Accessed August 9, 2015. http://dschool.stanford.edu/our-poin t-of-view/\#design-thinking

30. Balady GJ, Williams MA, Ades PA, et al. Core components of cardiac rehabilitation/secondary prevention programs: 2007 update. Circulation. 2007;115(20):2675-2682. doi:10.1161/circulationah a.106.180945

31. Mitchell DH, Swift G, Gilbert GL. Surgical wound infection surveillance: the importance of infections that develop after hospital discharge. Aust N Z J Surg. 1999;69:117-120. doi:10.1046/i.1440-1622.1999.0150 $\underline{0 . x}$
32. Iyer R, Gentry-Maharaj A, Nordin A, et al. Patientreporting improves estimates of postoperative complication rates: a prospective cohort study in gynaecological oncology. Br J Cancer.

2013;109(3):623-632. doi:10.1038/bjc.2013.366

33. Petherick ES, Dalton JE, Moore PJ, Cullum N. Methods for identifying surgical wound infection after discharge from hospital: a systematic review. BMC Infect Dis. 2006;6(1):170. doi:10.1186/1471-233 $\underline{4-6-170}$

34. Horan TC, Gaynes RP, Martone WJ, Jarvis WR, Emori TG. CDC definitions of nosocomial surgical site infections, 1992: a modification of CDC definitions of surgical wound infections. Infect Control Hosp Epidemiol. 1992;13(10):606-608. doi:10.1017/s019594 $\underline{1700015241}$

35. Center for Disease Control (CDC). Surgical Site Infection (SSI) Event. Procedure Associated Module (SSI), Atlanta, GA.; 2015. http://www.cdc.gov/nhsn/C PTcodes/ssi-cpt.html

36. Center for Disease Control (CDC). Prevention. Pneumonia (ventilator-associated [VAP] and nonventilator-associated pneumonia [PNEU]) event. Device-associated Module PNEU/VAP. Accessed August 15, 2015. http://www.cdc.gov/nhsn/PDFs/psc Manual/6pscVAPcurrent.pdf

37. The WHOQOL Group. WHOQOL-BREF: Introduction, administration, scoring, and generic version of the assessment. Programme on World Health, World Health Organization. Published online 1996.

38. Hibbard JH, Mahoney ER, Stock R, Tusler M. Selfmanagement and health care utilization. Health Serv Res. 2007;42(4):1443-1463. doi:10.1111/j.1475-6773.2 006.00669.x

39. Gordon JC. Beyond knowledge: Guidelines for effective health promotion messages. J Ext. 2002;40:7.

40. Mosen DM, Schmittdiel J, Hibbard J, Sobel D, Remmers C, Bellows J. Is patient activation associated with outcomes of care for adults with chronic conditions? J Ambul Care Manage. 2007;30(1):21-29. $\underline{\mathrm{d}}$ oi:10.1097/00004479-200701000-00005

41. Bittl JA. Family presence during catheterization procedures. Catheter Cardiovasc Interv. 2014;83(2):341-341. doi:10.1002/ccd.25041 